\title{
Evaluation in Indigenous Contexts: An Introduction to Practice
}

\author{
Robert P. Shepherd and Katherine A. H. Graham \\ Carleton University
}

\section{SETTING A BETTER DIRECTION FOR EVALUATION IN INDIGENOUS CONTEXTS}

Indigenous evaluation as a field of inquiry and finding culturally appropriate and responsive ways to evaluate Indigenous programs and services are receiving increased attention (Cram, Tibbetts, \& LaFrance, 2018). One important catalyst has been the Truth \& Reconciliation Commission of Canada's admonitions regarding the cultural damage caused by residential schools, where recommendations focus on the need for governments to pay greater attention to culturally relevant approaches to research, including program evaluations (TRC, 2015). More generally, Western governments are struggling to evaluate programs in Indigenous communities in ways that serve both governmental interests in accountability and quality assurance, while at the same time serving Indigenous needs and interests for program effectiveness and respecting local autonomy (Shepherd, 2018).

During the 2015 federal election, Liberal Party leader Justin Trudeau called on Canadians to support change through reconciliation and a renewed nation-tonation relationship between the federal government and the Indigenous peoples of Canada. The government has since committed to reforming the nation-tonation relationship, which has been evident in the Prime Minister's 2015 mandate letters to his ministers and the Principles respecting the Government of Canada's Relationship with Indigenous Peoples made public by then-minister of justice Jody Wilson-Raybould in July 2017 (Minister of Justice, 2017). In the mandate letters, the Prime Minister calls for a renewed nation-to-nation relationship with Indigenous peoples "based on recognition of rights, respect, cooperation and partnership" (Trudeau, 2015). More recently, the Prime Minister has said that recognition is necessary so that we can "get to a place where Indigenous peoples in Canada are in control of their own destiny, making their own decisions about their future." The Principles say that this is the promise of Section 35 of the Constitution and that they commit the government to advancing the UNDRIP's "call to respect and promote the inherent rights of Indigenous peoples."

In practice, the federal government committed to focus on supporting Indigenous peoples' governance initiatives in a way that can enable Indigenous governments and the federal, provincial, and territorial governments to work as partners within Canada's constitutional framework. This commitment extends to First Nations, Métis and Inuit communities. This is again consistent with UNDRIP, which maintains, "it is the mutual responsibility of all governments to shift 
their relationships and arrangements with Indigenous peoples so that they are based on recognition and respect for the rights to self-determination, including the inherent right to self-government for Indigenous nations" (UN Office of the High Commissioner for Human Rights, 2013). This is where Indigenous evaluation enters as a source of evidence in the context of recognition and respect, efforts to build capacity among all parties to the relationship, and development of models of reflection and control in the areas of programming, finance, and governance.

So far, little has been offered in the academic literature regarding the transformation of evaluation in light of this new paradigm of relations. A recent edition of New Directions in Evaluation on Indigenous evaluation makes the case for innovations in evaluation that meet the contextual needs of Indigenous peoples (Cram et al., 2018). Its focus is on contextual differences between Indigenous and non-Indigenous approaches to evaluation. This is an important contribution, but it is only part of the greater discussion needed to advance evaluation practice in this area. Specifically, this CJPE volume attempts to examine evaluation at the community and regional/organizational levels, along with the challenges inherent in governmental evaluation in these varied contexts. Aside from acknowledging that there are indeed conceptual differences in approach at the broad level of epistemology, there are also challenges of axiology, ontology, and methodology, as determined by such factors as language, cultural norms and practices, governance of evaluation and research, community decision making, and what is accepted as evidence in decision making.

In terms of past performance, it has been noted that the contribution of evaluations of Indigenous programs to better public policy making have been limited at best (Cram, Chilisa, \& Mertens, 2016; Cram \& Mertens, 2015). This has been seen as a result of the imposition of Western post-positivist approaches (Bowman, 2017; Chilisa, 2012; Mertens, 2018; Shepherd, 2018). Indeed, evaluation in many Indigenous communities is seen as something done "to them" rather than "with them" or even "for them" (Cram et al., 2018, p. 8; Wehipeihana, 2018). As a consequence, there have been many calls from outside the field of evaluation to do better (Bowman, 2017; Pasternak, 2017) and to recognize the participation of Indigenous community members in any research and evaluation endeavour that affects them. This message has been reinforced by the recent calls of the Truth and Reconciliation Commission to shift the balance of focus from Western approaches to Indigenous ways of knowing (broadly defined).

Within the past decade, the evaluation literature has begun to categorize Indigenous approaches to evaluation. Some scholars such as Mertens and Wilson (2012) frame it in the transformative school of thought, given the focus on understanding power dynamics within program designs, and who interventions privilege. Likewise, Chilisa (2012) and Cram (2016), and most recently Mertens (2018), refer to Indigenous evaluation as a separate paradigm given the distinct history of colonization in many settler countries, which includes, but is not limited to loss of land, resources, exclusion from governmental policymaking, and 
outright policies of termination. More broadly, differences in spirituality and collective identity among Indigenous peoples and between Indigenous peoples and settler populations have been recognized. One result is that Indigenous relations have been treated uniquely in the academic literature compared with those of other marginalized groups (Kymlicka, 2009). More specifically, there is burgeoning recognition not only that evaluation in Indigenous contexts must be thought of as distinct from other forms of evaluation inquiry but also that the ontology and epistemology of evaluation in these contexts merit a different way of conceiving of evaluation designs, data gathering, and reporting results.

For non-Indigenous governments that work with Indigenous communities and organizations, there is a struggle given new ethical and ontological imperatives that emanate from public commentary, such as the TRC's call for better ways to carry out evaluations that meet local needs for evidence, rather than a focus on fiscal or programmatic accountability at the donor government level. Evaluation as a field has yet to figure out how to make a contribution to evidence that aligns with Indigenous ways of knowing and also meets the varied purposes of donor governments. This special issue explores this challenge as well.

Therefore, the papers in this volume are about understanding the role, approach, and application of evaluation in Indigenous contexts using several policy fields as a reference. Each of the authors has worked in the Indigenous space for many years, either as an Indigenous or non-Indigenous evaluator, and has observed the strengths and limitations of Western-based approaches across several Indigenous contexts. The idea behind the volume is to highlight where the different policy fields and contexts may be converging and diverging in practice and experience. However, central to each of the papers is the common understanding that there are fundamental differences in ontology and epistemology between working in Indigenous contexts and other contexts, and how these can be balanced with governmental expectations for performance. The key sources of difference explained in the next section underpin the articles that follow.

\section{IDENTIFYING ONTOLOGICAL AND EPISTEMOLOGICAL DIFFERENCE}

There are many factors and risks to consider when bringing or bridging Indigenous cultural knowledge into Western research spaces such as evaluation. These include the potential for cultural dominance and appropriation, misinterpretation, and the dismissals that come with introducing Indigenous ways of knowing into the academy (Smith, 1999, pp. 99-103). Nonetheless, the admonitions of the Royal Commission on Aboriginal Peoples (RCAP) in 1996, and more recently the Truth \& Reconciliation Commission in 2016, have resulted in growing acceptance in the academy and governmental policy circles that Indigenous nations and communities are different in their understanding and approach to identity and ways of knowing. There is further recognition that this identity should be 
understood if reconciliation is to have any probability of success in policymaking or the results of evaluations. There is growing acceptance that to be Indigenous is, by definition, to be culturally, socially, and politically distinct (Battiste, 2007; Bowman, 2017).

The basis of difference between Western and Indigenous ontology and epistemology can be traced to what Groh (2018, p. 56) refers to as the "Tenets of Indigeneity," which serve to provide context or points of reference. These tenets should inform the work of evaluation in Indigenous contexts. The first tenet is that Indigenous people regard themselves as descendants of those who lived on their lands well before colonization (historical continuity). Second, it is accepted that Indigenous peoples are inextricably linked to their territory through having lived there before others with a relationship to those lands. Third, Indigenous peoples, by virtue of their own perseverance, maintain certain cultural features and value these as worthy to pass to future generations. It is further accepted that each Indigenous society is different from other peoples and even that communities vary one from another, further influencing self-identity. Fourth, Indigenous peoples have experienced a collective suppression of their cultures, expressed through discrimination, subjugation, dispossession, and various forms of cultural or other diminishment. Although defining Indigenous identity is highly contestable by virtue of the fact that it is not homogenous (Kovach, 2009, pp. 23-39), it does not minimize the need or the collective will to recognize difference and find appropriate approaches to bridge ontological and epistemological constructs in a way that enhances social collective understanding.

In Western ontological and epistemological paradigms, there is an underlying assumption that knowledge is understood individually and is superior, and that conveyance of that knowledge is also done on an individual basis in ways that privilege Western ways of knowing (Bortolin, 2011). By contrast, in most Indigenous ontologies, "knowledge is relational" (Wilson, 2001, p. 176). Wilson (2008, p. 73). Wilson maintains that most Indigenous ontologies value multiple understandings of reality as emanating from individuals and communities but that each has its own relationship with that reality. By contrast, in Western understandings of constructivism, each individual has a relationship with the object, policy, program, or social construct. That is, Indigenous ontologies regard reality as a process of relationships, and "Indigenous ontology is actually the equivalent of an Indigenous epistemology" (Wilson, 2001, p. 176). Language can reflect this difference. In English, objects are named (e.g., chair, house, lawn), whereas in many Indigenous languages, verbs are more prevalent to describe the uses of the object or one's relationship to it rather than labels. In Indigenous epistemology, it is likewise with people: relationships are multiple. Someone can be an aunt to one person, and a sister to someone else-knowledge is relational, and knowledge creation is shared. As Wilson (2008, p. 74) explains,

They thus include interpersonal, intrapersonal, environmental and spiritual relationships, and relationships with ideas. Indigenous epistemology is our cultures, our 
worldviews, our times, our languages, our histories, our spiritualities and our places in the cosmos. Indigenous epistemology is our systems of knowledge in their context, or in relationship.

At the ethical (axiological) core of such relationships is respect. Respect for self and each other is most certainly a base principle. However, also core to Indigenous ontologies and epistemologies is a respect for relationships between people, places, and objects that does not impinge on what is considered appropriate boundaries in representation, authorities, sovereignties and social and political contexts. As Wilson (2008, p. 77) describes it, "Indigenous axiology is built upon the concept of relational accountability. Right or wrong; validity; statistically significant; worthy or unworthy; value judgements lose their meaning. What is more important and meaningful is fulfilling a role and obligations in the research relationship." Such conceptions extend beyond traditional Western notions of constructivism, where there remains the idea that there be an appropriate separation between the researcher and the "object" of research. More contemporary notions of constructivism in transformative evaluation epistemologies would maintain that researchers must have points of reference within the relationships being built, which involves helping to build the relationships through the process of knowing. The researcher, therefore, develops respect in the relationship by creating a vested interest that the results are useful to both the community and research endeavour: there must be respect, reciprocity, and responsibility (Guba \& Lincoln, 2000; Weber-Pillwax, 2001).

\section{PAPERS CONTRIBUTED TO THIS SPECIAL EDITION}

The articles in this special edition are intended to frame the core context and issues pertaining to shifting the paradigm and practices of evaluation from Western and colonial models to approaches that reflect the reality of Western-Indigenous relationships and transformational needs. The first three articles in this volume frame the issues, while the latter four contributions provide more applied insights into the realities of the moment and the assets and challenges associated with moving forward in a good way. We then offer a brief conclusion that attempts to identify priorities for moving forward.

Pamela McCurry's article sets the scene from a legal perspective. The constitutional and legal context of Indigenous policy and programming is Canada is crucial. The evaluation community must understand that Section 35 of the Constitution Act, which affirms Indigenous rights, has been consistently interpreted by the courts to affirm specific rights related to Indigenous governance. McCurry demonstrates how this sets the foundation for reform of relationships and practices in the evaluation of Indigenous programs and in development of future policy.

Michelle Firestone has contributed a practice note that illustrates in a very concrete way how a group of respected Indigenous health and social service 
advisors were able to use relational practices to develop decolonizing principles and protocols that support community self-determination, centralize (but not homogenize) Indigenous cultures and worldviews, and provide guidelines to inform health and social service evaluation going forward.

Larry Bremner and Nicole Bowman share the theoretical and methodological roots of EvalIndigenous, established in 2012 under the global EvalPartners initiative to connect legislators and academics with practitioners. They discuss the theoretical and methodological roots of EvalIndigenous, which are grounded in tribal critical and Indigenous theories and methods and which consistently respect local Indigenous community agendas and philosophies. They highlight the implications of the work of EvalIndigenous for future evaluation policies and strategies.

Robert Shepherd and Katherine Graham contribute a piece that highlights some of the gaps in the evaluation literature about ways to improve evaluators' understanding of Indigenous ontologies and epistemologies and how to bridge these in practical ways with Western ways of knowing. They illustrate the challenges of doing this based on their own experiences with the Indigenous Youth Futures Partnership, a community-based project designed to improve the resilience of and prospects for youth in northwestern Ontario First Nations. They conclude that trust is a fundamental condition that is needed to move the evaluation effort forward and that serves the reciprocal needs of communities and other users.

Gerald McKinley reflects on his continuing journey as a learner as a community-based partner in child and mental health programs in several Anishinaabek communities in Ontario. He focuses on the implications and impact of Mertens's work, which underpins evaluation with a foundation of social justice and human rights principles, on his practice as a medical anthropologist doing evaluation.

Kim Scott focuses on the recognition of Indigenous moral authority and how to recognize the assets and strengths of Indigenous communities in transformational times. She deals specifically with how to build an asset-based approach to policy and program development and evaluation in the transition of Indigenous communities from dependence on diesel for heating and electricity to renewable energy.

Debbie Delancey rounds out the volume by contributing a history of evaluation in the Northwest Territories (NWT). She analyzes the impact of the everchanging governance landscape in the NWT, as the territorial government develops new and evolving relationships with First Nations and Inuvialuit governments and organizations emerging out of modern treaties. This has significant implications for evaluation, including an emerging interest in the practical working relationship between Indigenous evaluation and Western approaches.

This edition of the journal concludes with a call to action. It argues for Indigenous evaluation to be a separate branch on the "evaluation tree" (Alkin, 2012) from Western and transformative evaluation (Mertens \& Wilson, 2012). Based on the other contributions to this volume, we begin the process of identifying an 
agenda for the Canadian Evaluation Society to move forward. There have been some positive and foundational developments at the national level, particularly as part of CES national conference proceedings since the Report of the Truth and Reconciliation Commission, including a policy commitment to better respect Indigenous ways of knowing in fieldwork. We argue, however, that real work is required at the CES chapter level to build practical knowledge and provide the foundation for the new relationships that are essential if the field of evaluation is to contribute positively to our reality. The process begins with awareness-building and the need to relinquish some control over evaluation projects.

\section{REFERENCES}

Alkin, M. (2012). Evaluation roots: A wider perspective of theorists' views and influences. Thousand Oaks, CA: Sage.

Battiste, M. (2007). Research ethics for protecting Indigenous knowledge and heritage: Institutional and researcher responsibilities. In N. Denzin \& M. Giardina (Eds.), Ethical futures of qualitative research: Decolonizing the politics of knowledge (pp. 111-127). Walnut Creek, CA: Left Coast Press.

Bortolin, K. (2011). Serving ourselves: How the discourse on community engagement privileges the university over the community. Michigan Journal of Community Service Learning, 18(1), 49-58. Retrieved from http://hdl.handle.net/2027/ spo.3239521.0018.104

Bowman, N. (2017). Asserting tribal sovereignty in evaluation and policy studies. Tribal Leader/Scholar Forum of the National Congress of American Indians-Policy Research Institute. Uncasville, CT. Retrieved from https://www.ncai.org/policy-research-center/ initiatives/tribal-leader-scholar-forum

Chilisa, B. (2012). Indigenous research methodologies. Thousand Oaks, CA: Sage.

Cram, F. (2016). Lessons on decolonizing evaluation from Kaupapa Maori evaluation. Canadian Journal of Program Evaluation, 3(30), 296-312. https://doi.org/10.3138/ cjpe.30.3.04

Cram, F., Chilisa, B., \& Mertens, D. M. (2016). The journey begins. In D. M. Mertens, F. Cram, \& B. Chilisa (Eds.), Indigenous pathways into social research: Voices of a new generation (pp. 11-40). New York, NY: Left Coast Press.

Cram, F., \& Mertens, D. M. (2015). Transformative and Indigenous frameworks for multimethod and mixed methods research. In S. Hesse-Biber \& B. Johnson (Eds.), The Oxford handbook of multi-methods and mixed methods research inquiry (pp. 91-110). New York, NY: Oxford University Press.

Cram, F., Tibbetts, K. A., \& LaFrance, J. (2018). Editor's notes: A stepping stone in indigenous evaluation. New Directions for Evaluation, 2018(159), 7-16. https://doi. org/10.1002/ev.20327

Groh, A. (2018). Research methods in indigenous contexts. Cham, Switzerland: Springer.

Guba, E., \& Lincoln, Y. (2000). Paradigmatic controversies, contradictions, and emerging confluences. In N. Denzin, \& Y. S. Lincoln (Eds.), Handbook of qualitative research (pp. 163-188). Thousand Oaks, CA: Sage. 
Kovach, M. (2009). Indigenous methodologies: Characteristics, conversations, and contexts. Toronto, ON: University of Toronto Press.

Kymlicka, W. (2009). Multicultural odysseys: Navigating the new international politics of diversity. London, England: Oxford University Press.

Mertens, D. M. (2018). Mixed methods design in evaluation. Thousand Oaks, CA: Sage.

Mertens, D. M., \& Wilson, A. T. (2012). Program evaluation theory and practice: A comprehensive guide. New York, NY: Guilford Press.

Minister of Justice. (2017). Principles respecting the Government of Canada's relationship with Indigenous peoples. Retrieved from https://www.justice.gc.ca/eng/csj-sjc/ principles-principes.html

Pasternak, S. (2017). Grounded authority: The Algonquins of Barriere Lake against the State. Minneapolis, MN: University of Minnesota Press.

Shepherd, R. P. (2018). Indigenous peoples and the reconciliation agenda: Funding, accountability, and risk. In C. Dunn (Ed.), The handbook of Canadian public administration (3rd ed., pp. 246-268). Toronto, ON: Oxford University Press.

Smith, L. T. (1999). Decolonizing methodologies: Research and indigenous peoples. New York, NY: Palgrave.

TRC. (2015). Final report of the Truth and Reconciliation Commission of Canada. Toronto, ON: James Lorimer \& Co.

Trudeau, J. (2015). Mandate Letters to Ministers. Retrieved from https://pm.gc.ca/en/ mandate-letters

UN Office of the High Commissioner for Human Rights. (2013). Declaration on the Rights of Indigenous Peoples. Retrieved from https://www.refworld.org/docid/5289e4fc4. html

Weber-Pillwax, C. (2001). What is Indigenous research? Canadian Journal of Native Education, 25(2), 166-174.

Wehipeihana, N. (2018). Affirming and privileging Indigenous knowledge in evaluation. Canadian Evaluation Society 2018. Calgary. Retrieved from http://nwtevaluation2018. com/presentations.html

Wilson, S. (2001). What is an Indigenous research methodology? Canadian Journal of $\mathrm{Na}$ tive Education, 25(2), 175-179.

Wilson, S. (2008). Research is ceremony: Indigenous research methods. Black Point, NS: Fernwood.

\section{AUTHOR INFORMATION}

Robert P. Shepherd is associate professor at the School of Public Policy \& Administration at Carleton University. His research spans public management and governmental reform, Indigenous public management, ethics, and policy and program evaluation. He is interested in how public accountability and oversight systems intersect to improve overall public management and governance systems. In addition, his research extends to understanding how governmental program evaluation functions can improve public policy and decision making. 
Katherine A. H. Graham is professor emerita at the School of Public Policy \& Administration at Carleton University. Her research interests concern Indigenous and northern development policy, urban and local governance, and institutional reform in government. Community-based research is an important pillar of her work. She is the founding coordinator of the Carleton University Institute on the Ethics of Research with Indigenous Peoples (CUIERIP). Katherine is currently working on youth and community capacity building in northwestern Ontario. 